\title{
In situ Forming Hyperbranched PEG - Thiolated Hyaluronic Acid Hydrogels With Honey-Mimetic Antibacterial Properties
}

OPEN ACCESS

Edited by:

Giovanni Vozzi,

University of Pisa, Italy

Reviewed by:

Jennifer Patterson,

Instituto IMDEA Materiales, Spain

Khoon Lim,

University of Otago, Christchurch,

New Zealand

*Correspondence:

Jochen Salber

jochen.salber@rub.de

Valeria Chiono

valeria.chiono@polito.it

${ }^{+}$These authors have contributed equally to this work and share first authorship

FThese authors have contributed equally to this work and share senior authorship

Specialty section: This article was submitted to Biomaterials,

a section of the journal Frontiers in Bioengineering and Biotechnology

Received: 15 July 2021 Accepted: 28 September 2021 Published: 16 November 2021

Citation:

Vasquez JM, Idrees A, Carmagnola I, Sigen A, McMahon S, Marlinghaus L, Ciardelli G, Greiser U, Tai H, Wang W, Salber J and Chiono V (2021) In situ

Forming Hyperbranched

PEG - Thiolated Hyaluronic Acid Hydrogels With Honey-Mimetic Antibacterial Properties.

Front. Bioeng. Biotechnol. 9:742135. doi: 10.3389/fbioe.2021.742135
Jeddah Marie Vasquez ${ }^{1,2,3+}$, Ayesha Idrees ${ }^{1,4+}$, Irene Carmagnola ${ }^{1}$, Aa Sigen $^{2,3}$, Sean McMahon ${ }^{2,3}$, Lennart Marlinghaus ${ }^{5}$, Gianluca Ciardelli ${ }^{1}$, Udo Greiser ${ }^{3}$, Hongyun Tai ${ }^{2}$, Wenxin Wang ${ }^{2,3}$, Jochen Salber ${ }^{4 * \pm}$ and Valeria Chiono ${ }^{1 * \neq}$

${ }^{1}$ Department of Mechanical and Aerospace Engineering, Politecnico di Torino, Turin, Italy, ${ }^{2}$ Blafar Ltd., Dublin, Ireland, ${ }^{3}$ Wenxin Wang Research Group, Charles Institute of Dermatology, University College Dublin, Dublin, Ireland, ${ }^{4}$ Department of Surgery, Universitätsklinikum Knappschaftskrankenhaus Bochum, Ruhr-University, Bochum, Germany, ${ }^{5}$ Department of Medical Microbiology, Ruhr-University Bochum, Bochum, Germany

The rapidly increasing resistance of bacteria to currently approved antibiotic drugs makes surgical interventions and the treatment of bacterial infections increasingly difficult. In recent years, complementary strategies to classical antibiotic therapy have, therefore, gained importance. One of these strategies is the use of medicinal honey in the treatment of bacterially colonized wounds. One of the several bactericidal effects of honey is based on the in situ generation of hydrogen peroxide through the activity of the enzyme glucose oxidase. The strategy underlying this work is to mimic this antibacterial redox effect of honey in an injectable, biocompatible, and rapidly forming hydrogel. The hydrogel was obtained by thiol-ene click reaction between hyperbranched polyethylene glycol diacrylate (HB PEGDA), synthesized using reversible addition-fragmentation chain transfer (RAFT) polymerization, and thiolated hyaluronic acid (HA-SH). After mixing $500 \mu \mathrm{L}$ HB PEGDA (10\%, w/w) and $500 \mu \mathrm{L} \mathrm{HA}$ $\mathrm{SH}(1 \%, \mathrm{w} / \mathrm{w})$ solutions, hydrogels formed in 60 s (HB PEGDA/HA-SH 10.0-1.0), as assessed by the tube inverting test. The HB PEGDA/HA-SH 10.0-1.0 hydrogel (200 $\mu \mathrm{L})$ was resistant to in vitro dissolution in water for at least 64 days, absorbing up to $130 \mathrm{wt} \%$ of water. Varying glucose oxidase (GO) amounts (0-500 U/L) and constant glucose content (2.5 wt\%) were loaded into HB PEGDA and HA-SH solutions, respectively, before hydrogel formation. Then, the release of $\mathrm{H}_{2} \mathrm{O}_{2}$ was evaluated through a colorimetric pertitanic acid assay. The $\mathrm{GO}$ content of $250 \mathrm{U} / \mathrm{L}$ was selected, allowing the formation of $10.8 \pm 1.4 \mathrm{mmol} \mathrm{H}_{2} \mathrm{O}_{2} / \mathrm{L}$ hydrogel in $24 \mathrm{~h}$, under static conditions. The cytocompatibility of HB PEGDA/HA-SH 10.0-1.0 hydrogels loaded with different $\mathrm{GO}$ activities $(\leq 500 \mathrm{U} / \mathrm{L})$ at a constant glucose amount (2.5 wt \%) was investigated by in vitro assays at $24 \mathrm{~h}$ with $\mathrm{L} 929$ and $\mathrm{HaCaT}$ cell lines, according to DIN EN ISO 10993-5. The tests showed cytocompatibility for GO enzyme activity up to $250 \mathrm{U} / \mathrm{L}$ for both cell lines. The antibacterial activity of HB PEGDA/HA-SH 10.0-1.0 hydrogels loaded with increasing amounts of $\mathrm{GO}$ was demonstrated against various gram-positive bacteria ( $S$. aureus and S. epidermidis), antibiotic-resistant gram-positive bacteria (MRSA and MRSE), gramnegative bacteria (P. aeruginosa, E. coli, and A. baumanii), and antibiotic-resistant gramnegative strains $(P$. aeruginosa and $E$. coll) using agar diffusion tests. For all gram-positive 
bacterial strains, increasing efficacy was measured with increasing GO activity. For the two $P$. aeruginosa strains, efficacy was shown only from an enzyme activity of $125 \mathrm{U} / L$ and for $E$. coli and $A$. baumanii, efficacy was shown only from $250 \mathrm{U} / \mathrm{L}$ enzyme activity. HB PEGDA/HA-SH 10.0-1.0 hydrogels loaded with $\leq 250 \mathrm{U} / \mathrm{L} \mathrm{GO}$ and $2.5 \mathrm{wt} \%$ glucose are promising formulations due to their fast-forming properties, cytocompatibility, and ability to produce antibacterial $\mathrm{H}_{2} \mathrm{O}_{2}$, warranting future investigations for bacterial infection treatment, such as wound care.

Keywords: antibacterial, hyaluronic acid, hyperbranched PEG, thiol-ene click chemistry, honey-mimetic hydrogel, dressing, wound care

\section{INTRODUCTION}

The huge problem of antibacterial resistance to antibiotics has increased the demand for drug-free antimicrobial strategies, and this has led to reevaluation of ancient antibacterial remedies, such as those derived from natural products, including honey (Mandal and Mandal, 2011).

Research has been conducted on manuka (L. scoparium) honey, which has been demonstrated to be effective against several human pathogens, including Escherichia coli (E. coli), Enterobacter aerogenes, Salmonella typhimurium, Staphylococcus aureus ( $S$. aureus), $\beta$-haemolytic streptococci, vancomycinresistant enterococci (VRE), and Pseudomonas aeruginosa ( $P$. aeruginosa) (Mandal and Mandal, 2011; Shenoy et al., 2012).

Honey has been widely studied for its bactericidal effects (Shenoy et al., 2012; Albaridi, 2019). Such antibacterial properties are attributed to many factors, including phytochemical components, osmotic effect of sugar on bacterial cells, acidic $\mathrm{pH}$ that helps macrophages in destroying bacteria, and the enzymatic activity of GO to produce in situ hydrogen peroxide from glucose (Bogdanov 1997; Abuharfeil et al., 1999; Cooper et al., 1999; Cooke et al., 2015). Particularly, hydrogen peroxide represents the main antimicrobial agent in honey: its concentration is determined by relative levels of glucose oxidase and glucose according to the following reaction (Wong et al., 2008; Mandal and Mandal, 2011):

$$
\beta-D-\text { Glucose }+\mathrm{O}_{2} \stackrel{\text { Glucose Oxidase }}{\longrightarrow} \mathrm{D}-\text { gluconolactone }+\mathrm{H}_{2} \mathrm{O}_{2} \text {. }
$$

Reactive oxygen species (ROS), such as hydrogen peroxide, play a pivotal role in the orchestration of the normal woundhealing response. They act as secondary messengers to many immunocytes and nonlymphoid cells, which are involved in the repair process (Dunnill et al., 2017). Harnessing the potential of ROS to be used within wound care devices, provides the ability to accelerate the healing process and to prevent bacterial infection (Loo et al., 2012). There are several ROS-based technologies currently available in the market or applied in research for wound applications. Among them is SurgihoneyRO ${ }^{\mathrm{TM}}$, a commercially available antibacterial product based on a bioengineered honey gel, which enzymatically produces $\mathrm{H}_{2} \mathrm{O}_{2}$ from glucose oxidase and glucose after application to a wound (Cooke et al., 2015). Another ROS-based commercially available wound dressing is Oxyzyme (Moffatt et al., 2014). It consists of one hydrogel patch embedded with glucose, that is called the "wound contact patch" and a smaller hydrogel patch, called the "secondary wound patch," embedded with GO enzyme. Such hydrogels are stacked on top of each other, then a cover dressing is applied to protect the wound from exposure. The in situ formed hydrogen peroxide from Oxyzyme allows the oxidation of loaded iodide ions into iodine, exerting antimicrobial activity, and the formation of oxygen, favoring wound healing (Brimson and Nigam, 2013).

Previously, a quick forming $\mathrm{H}_{2} \mathrm{O}_{2}$-releasing hydrogel was reported based on gelatin-hydroxyphenyl propionic acid, which triggered cross-linking by horseradish peroxidase enzyme (HRP)/ $\mathrm{H}_{2} \mathrm{O}_{2}$ (Lee et al., 2017). The amount of $\mathrm{H}_{2} \mathrm{O}_{2}$ not involved in hydrogel formation served as the antibacterial component and was gradually released. The hydrogel showed antimicrobial activity against gram-positive bacteria including Staphylococcus aureus, S. epidermidis, and clinical isolate of methicillin-resistant S. aureus (MRSA). As a drawback, residual $\mathrm{H}_{2} \mathrm{O}_{2}$ was only passively released by the system up to exhaustion, while the hydrogel was not able to continuously produce antimicrobial $\mathrm{H}_{2} \mathrm{O}_{2}$. Recently, Zhang et al. prepared a photocrosslinked antifouling hydrogel from polyethylene glycol diacrylate containing $\mathrm{GO}$, to produce $\mathrm{H}_{2} \mathrm{O}_{2}$ in contact with glucose (Zhang et al., 2020). However, this hydrogel did not perfectly replicate antimicrobial honey-mimetic mechanisms as glucose was not added into the hydrogel.

Based on the current state of the art, this work aimed to produce an injectable, fast-forming, antibacterial hydrogel for future use in the treatment of wounds colonized or infected with bacteria that overcomes the limitations of other honey-mimetic products, such as the ability to adapt to each wound shape and release different amounts of $\mathrm{H}_{2} \mathrm{O}_{2}$ per hydrogel volume, depending on the individual wound situation. An ideal hydrogel for wound healing applications should form in situ within minutes under mild conditions. "Click" type chemical cross-linking was here exploited as a mechanism for rapid in situ formation of hydrogels (Kennedy et al., 2014). In detail, the hydrogel was formed by thiol-ene reaction between hyperbranched polyethylene glycol (PEG) diacrylate (HB PEGDA) and thiolated hyaluronic acid (HA-SH). HA was selected as it is one of the natural components of the dermal extracellular matrix (ECM) and has important functions during wound healing: it regulates inflammatory response and promotes fibroblast migration and proliferation (Dong et al., 2012; Loebel et al., 2017; Poldervaart et al., 2017). On the other hand, PEG is advantageous due to its nonimmunogenicity and resistance to 
<smiles>C=CC(=O)OCCOC(C)=O</smiles>

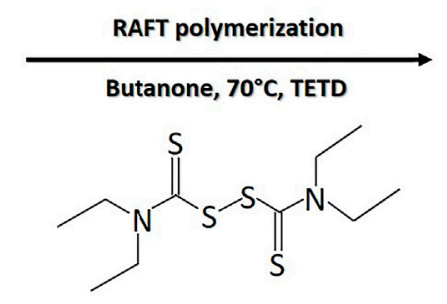

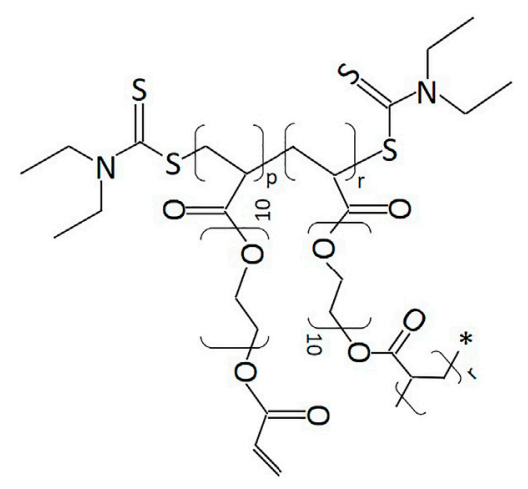

FIGURE 1 | RAFT polymerization reaction of PEG-diacrylate for HB PEGDA synthesis $(p=0.45)(r=0.55)$.

protein adsorption (Dong et al., 2015). Thiol-ene crosslinking of the mixed system may impart to wound closure retard superior resistance to hyaluronidase-catalyzed degradation of HA and represents a tool to modulate hydrogel mechanical properties. Recently, Wenxin's lab has prepared HB PEGDA/HA-SH hydrogels and exploited them to support adipose stem cellsbased therapy, demonstrating their biocompatibility (Zhang et al., 2018).

In this work, HB PEGDA/HA-SH hydrogels were prepared from HB PEGDA solution (containing GO) and HA-SH solution (containing glucose, G). Physical encapsulation of GO may protect the enzyme from degradation at the wound site with respect to topical application (Arul et al., 2012). The interaction between $\mathrm{GO}$ and $\mathrm{G}$ causes the formation of antibacterial $\mathrm{H}_{2} \mathrm{O}_{2}$. By manipulating the concentrations of $\mathrm{GO}$ at constant $\mathrm{G}$ content within the hydrogel, the rate of formation and release of $\mathrm{H}_{2} \mathrm{O}_{2}$ was controlled. Loo et al. previously demonstrated that daily topical application of $\mathrm{H}_{2} \mathrm{O}_{2}$ solution $(15 \mu \mathrm{L})$ with varying concentrations $(10-166 \mathrm{mM})$ on skin wounds in C57/BL6 mice for overall 10 days caused different effects, from enhanced angiogenesis ( $10 \mathrm{mM}$ concentration, i.e., $0.15 \mu \mathrm{mol} /$ wound) to wound closure retard $(166 \mathrm{mM}$ concentration, i.e., $2.5 \mu \mathrm{mol} /$ wound) (Loo et al., 2012). In this work, tuning the amount of GO in HB-PEGDA/HA-SH hydrogels at fixed G content allowed the release of suitable $\mathrm{H}_{2} \mathrm{O}_{2}$ concentrations per hydrogel volume within $24 \mathrm{~h}$, which were able to control various gram-positive and gram-negative bacterial strains while largely avoiding cytotoxic effects in 2D cultures of L929 mouse fibroblasts and $\mathrm{HaCaT}$ human keratinocytes.

\section{MATERIALS AND METHODS}

\section{Materials}

2,2'-Azobis(isobutyronitrile) (AIBN), tetraethylthiuram disulfide (TETD), polyethylene glycol diacrylate (PEGDA; Mw: $575 \mathrm{Da}$ ), butanone, hexane, diethyl ether, dimethyl formamide (DMF), acetone, lithium bromide ( $\mathrm{LiBr}$ ), glucose, glucose oxidase enzyme (E.C. 1.1.3.4), phosphate-buffered saline at pH 7.4 (PBS), Hank's buffer solution, high-glucose Dulbecco's modified Eagle's medium (DMEM), foetal bovine serum (FBS), resazurin sodium salt, and penicillin-streptomycin (PS) were supplied from Sigma-Aldrich, United Kingdom. Thiolated hyaluronic acid (HA-SH, 80\% degree of thiolation, $400 \mathrm{kDa}$ ) was provided by Blafar, Ireland.

\section{Synthesis of Hyperbranched PEG-Diacrylate}

HB PEGDA was synthesized via reversible additionfragmentation chain transfer (RAFT) polymerization, through the reaction illustrated in Figure 1. Briefly, in a $250 \mathrm{ml}$ doubleneck flask, the following reagents were dissolved in $160 \mathrm{ml}$ butanone: $46 \mathrm{~g}$ PEGDA, $948.92 \mathrm{mg}$ TETD (chain transfer agent), and $735.66 \mathrm{mg}$ AIBN (reaction initiator). The doubleneck flask was sealed and the reaction solution was purged with argon; afterward, the reaction vessel was placed into an oil bath at $70^{\circ} \mathrm{C}$ for $2-3 \mathrm{~h}$.

Samples were taken hourly to be analyzed by gel permeation chromatography/size exclusion chromatography (Agilent 1260 Infinity GPC/SEC system, Agilent Technologies, Santa Clara, CA, United States) to monitor the molecular weight increase of the polymer and the molar conversion. When the molecular weight reached $10-20 \mathrm{kDa}$, polymerization was stopped by quenching the flask with ice water and exposed to the air. The polymer was purified by precipitation in diethyl ether: hexane solution $(2: 1 \mathrm{v} /$ v) three times and then dried in a vacuum oven for $48 \mathrm{~h}$ to remove residual solvent.

\section{Chemical Characterization of HB PEGDA GPC/SEC Analysis}

Samples were prepared for GPC analysis (Agilent PL-GPC50) by dissolving $3 \mathrm{mg}$ of HB PEGDA in $1 \mathrm{ml}$ of DMF. Each solution was filtered using a syringe filter type Sartorius Minisart ${ }^{\mathrm{TM}}$ (glass fibre upstream filter combined with a $0.45 \mu \mathrm{m}$ pore size cellulose acetate filter, Fisher Scientific, United Kingdom) into a small amber GPC vial. The samples were analyzed by GPC/SEC to monitor number average molecular weight $(\mathrm{Mn})$, weight average molecular weight $(\mathrm{Mw})$, polydispersity index $(\mathrm{PDI}=\mathrm{Mw} / \mathrm{Mn})$, and the degree of polymerization (PD) as the reaction proceeded. The system was equipped with a refractive index detector (RI). The columns in series ( $30 \mathrm{~cm}$ PLgel Mixed-C, two in series) were 
eluted using DMF (containing $0.1 \% \mathrm{LiBr}$ ) as the mobile phase and calibrated with poly (methyl methacrylate) (PMMA) standards. All calibrations and analysis were performed at $60^{\circ} \mathrm{C}$ and with a flow rate of $1 \mathrm{ml} \mathrm{min}^{-1}$.

\section{${ }^{1} \mathrm{H}$ Nuclear Magnetic Resonance}

For characterizing molecular structure, ${ }^{1} \mathrm{H}$ nuclear magnetic resonance (NMR) was used. The polymer samples were dissolved in chloroform-D $\left(\mathrm{CDCl}_{3}\right)$ and ${ }^{1} \mathrm{H}$ NMR analysis was carried out on a $400 \mathrm{MHz}$ Varian NMR spectroscopy system. Data were analyzed using MesReNova 6.1 processing software. The chemical shifts were referenced to the lock chloroform $\left(\mathrm{CDCl}_{3}, 7.26 \mathrm{ppm}\right)$.

The branching ratio, i.e. the ratio of the branched to all PEGDA units, was calculated by the following equation (Dong et al., 2015):

$$
\begin{aligned}
\text { Branching ratio } & =1-\frac{\text { Linear PEGDA units }}{\text { All PEGDA units }} \\
& =1-\frac{\text { Integral of } y}{\text { Integral of } d / 4}
\end{aligned}
$$

with $y$ indicating the chemical shifts of pendant acrylate groups (in the 5.8-6.4 ppm range) and d indicating the chemical shifts of PEG groups (3.95-4.34 ppm range).

Furthermore, vinyl ratio, i.e., the amount of vinyl groups (mol \%) was also calculated (Zhang et al., 2018; Wang et al., 2015):

$$
\text { Vinyl ratio }=\frac{\text { Linear PEGDA units }}{\text { All PEGDA units }}=\frac{\text { Integral of } y}{\text { Integral of } d / 4} \text {. }
$$

\section{Preparation of the HB PEGDA/HA-SH 10.0-1.0 Hydrogel}

HB PEGDA/HA-SH 10.0-1.0 hydrogel formulations for the different physicochemical and biological characterizations were always freshly prepared for each experiment by homogeneously mixing equal volumes of $\mathrm{HB}$ PEGDA/1X PBS solution $(40 \% \mathrm{w} / \mathrm{w})$ and HA-SH/1X PBS solution $(4 \% \mathrm{w} /$ w) by vortexing vigorously.

\section{Gelation Time Measurement}

The gelation time for HB PEGDA/HA-SH 10.0-1.0 hydrogels was measured by the vial tilt method (Deshmukh et al., 2010). Briefly, $500 \mu \mathrm{L}$ HB PEGDA solution $(40 \% \mathrm{w} / \mathrm{w})$ was combined with $500 \mu \mathrm{L}$ HA-SH solution $(4 \% \mathrm{w} / \mathrm{w})$. The vials were tilted upside down and observed for $5 \mathrm{~s}$. Gelation was considered complete when no flow was observed within $5 \mathrm{~s}$. Measurements of gelation time were carried out in triplicate $(n=3)$.

\section{Water Uptake of Hydrogels}

In order to determine the water uptake profile, $200 \mu \mathrm{L} \mathrm{HB}$ PEGDA/HA-SH 10.0-1.0 hydrogel was placed in a preweighed $20 \mathrm{ml}$ scintillation vial and initially weighed. Then, $2 \mathrm{ml} 1 \mathrm{X}$ PBS was added to the vial and incubated at $37^{\circ} \mathrm{C}$. At different time points up to 6 weeks (every $2 \mathrm{~h}$ during the first $8 \mathrm{~h}$, every $24 \mathrm{~h}$ for the first week, and every 2 days onward), PBS was removed and the vials were weighed again. After weight measurement, $2 \mathrm{ml}$ fresh PBS solution was added again and the vial was replaced in the incubator. Measurements were performed in quadruplicates $(n=4)$.

Water uptake percentage was calculated as follows:

$$
\text { Water uptake }(\%)=\frac{W_{t}-W_{0}}{W_{0}} \times 100,
$$

where $W_{t}$ is the weight of the hydrogel at time point $t$ and $W_{O}$ is the initial weight of the hydrogel.

\section{Preparation of Honey-Mimetic HB PEGDA/ HA-SH Hydrogels by $G O$ and $G$ Encapsulation}

The $\mathrm{H}_{2} \mathrm{O}_{2}$-releasing hydrogel samples were prepared by mixing HB-PEGDA solution $(40 \% \mathrm{w} / \mathrm{w})$, containing various $\mathrm{GO}$ concentrations, with HA-SH $(4 \% \mathrm{w} / \mathrm{w})$ solution, containing constant G concentration (Supplementary Figure S1).

In detail, HB-PEGDA was dissolved in 1X PBS to prepare a $80 \%$ (w/w) stock solution. $1 \mathrm{U}$ is the amount of GO that catalyzes the conversion of $1 \mu \mathrm{M}$ glucose into $1 \mu \mathrm{M} \mathrm{H} \mathrm{H}_{2} \mathrm{O}_{2}$ within $1 \mathrm{~min}$ [Nomenclature Committee of the International Union of Biochemistry (NC-IUB), 1979]. The purchased GO was a lyophilized product with $19.290 \mathrm{U} / \mathrm{mg}$ activity. Enzyme stock solution was prepared as $10,000 \mathrm{U} / \mathrm{L}$ in $1 \mathrm{X}$ PBS. Enzyme solutions (Solution A, shown in Table 1; Supplementary Figure S1) were prepared from the enzyme stock solution by dilution with PBS. Same volumes of Solution A and HB-PEGDA solution $(80 \% \mathrm{w} / \mathrm{w})$ were mixed to obtain Solution B (Table 1; Supplementary Figure S1). HA-SH solution ( $4 \%$ w/w, Solution D, Supplementary Figure S1) containing 5\% (w/w) G (Solution C, Supplementary Figure S1) was prepared. HB PEGDA/HA-SH $10.0-1.0$ hydrogels with various GO concentrations and $2.5 \% \mathrm{w} / \mathrm{w}$ content were prepared (Table 1; Supplementary Figure S1).

For further investigations, hydrogel test specimens were prepared by mixing equal volumes (e.g., $15 \mu \mathrm{L}$ ) of Solution B with Solution C. Afterward, properly dispersed mixture was completely pipetted onto a Teflon ${ }^{\mathrm{TM}}$ plate surface. Following this protocol, semispherical hydrogel beads with $\sim 5 \mathrm{~mm}$ diameter were prepared. The HB PEGDA/HA-SH 10.0-1.0 hydrogel samples were named according to the concentration of encapsulated GO: PEGDA/HASH 10.0-1.0 500, 250, 125, 50, and $25 \mathrm{U} / \mathrm{L}$ GO, respectively.

\section{Analysis of Hydrogen Peroxide Released From HB PEGDA/HA-SH 10.0-1.0 Hydrogels} Hydrogels with different compositions (Table 1) were formed by mixing a volume of $100 \mu \mathrm{L}$ HB PEGDA/GO solution (Solution B) and $100 \mu \mathrm{L} \mathrm{HA}-\mathrm{SH} / \mathrm{G}$ solution (Solution C) into a $1 \mathrm{ml}$ Eppendorf tube. After the hydrogel was formed, $800 \mu \mathrm{L}$ of deionized $\mathrm{H}_{2} \mathrm{O}$ was added to the $200 \mu \mathrm{L}$ hydrogel sample and incubated at $37^{\circ} \mathrm{C}$. The formation of $\mathrm{H}_{2} \mathrm{O}_{2}$ was monitored at different time points between 2 and $24 \mathrm{~h}$. The production of $\mathrm{H}_{2} \mathrm{O}_{2}$ was quantified by a colorimetric pertitanic acid assay (Sigma-Aldrich, United Kingdom) 
TABLE 1 | HB PEGDA/HA-SH 10.0-1.0 hydrogels containing GO and G.

\begin{tabular}{|c|c|c|c|}
\hline $\begin{array}{l}\text { GO solution in } \\
\text { PBS (U/L) (Solution A) }\end{array}$ & $\begin{array}{c}\text { GO concentration in } \\
\text { HB PEGDA solution } \\
(40 \% \mathrm{w} / \mathrm{w})(\mathrm{U} / \mathrm{L}) \text { (Solution B) }\end{array}$ & $\begin{array}{c}\text { G concentration in } \\
\text { HA-SH solution }(4 \% \mathrm{w} / \mathrm{w}) \\
(w / w \%) \text { (Solution C) }\end{array}$ & $\begin{array}{c}\text { GO concentration in } \\
\text { the HB PEGDA/ } \\
\text { HA-SH } 10.0-1.0 \text { hydrogel (U/L) }\end{array}$ \\
\hline 100 & 50 & 5 & 25 \\
\hline 200 & 100 & 5 & 50 \\
\hline 500 & 250 & 5 & 125 \\
\hline 1,000 & 500 & 5 & 250 \\
\hline
\end{tabular}

according to the method by Eisenberg (1943). Briefly, $100 \mu \mathrm{L}$ of the release solution (containing in situ generated $\mathrm{H}_{2} \mathrm{O}_{2}$ ) was withdrawn at specific time points and placed in a 96-well plate. Then, $50 \mu \mathrm{L}$ of the assay solution $(2.5 \% \mathrm{w} / \mathrm{w}$ titanium oxysulfate in $2 \mathrm{M} \mathrm{H}_{2} \mathrm{SO}_{4}$ solution) was added. The color of the solution changed into yellow by $\mathrm{H}_{2} \mathrm{O}_{2}$ reaction with $\mathrm{Ti}(\mathrm{IV})$ (Supplementary Figure S2), according to the reaction:

$\mathrm{Ti}^{4+}+\mathrm{H}_{2} \mathrm{O}_{2}+2 \mathrm{H}_{2} \mathrm{O} \rightarrow \mathrm{H}_{2} \mathrm{TiO}_{4}($ pertitanic acid, yellow $)+4 \mathrm{H}^{+}$.

The amount of pertitanic acid formed, corresponding to the amount of $\mathrm{H}_{2} \mathrm{O}_{2}$ released by hydrogels, was derived from the absorbance intensity of the pertitanic acid solution at $407 \mathrm{~nm}$ wavelength, measured in a SpectraMax M3 multimode microplate reader (Molecular Devices, San José, CA, United States) equipped with SoftMax Pro software for data collection and analysis. For obtaining the calibration curve, $100 \mu \mathrm{L}$ of $\mathrm{H}_{2} \mathrm{O}_{2}$ solutions with $0-20 \mathrm{mM}$ concentrations were pipetted into the wells of a 96 -well plate. Then, $50 \mu \mathrm{L}$ of the prepared ROS assay solution was added into each well. The plate was shaken in the plate reader for $15 \mathrm{~s}$ before the absorbance intensity was read at $407 \mathrm{~nm}$ wavelength. Based on the calibration curve (Supplementary Figure S3), $\mathrm{H}_{2} \mathrm{O}_{2}$ concentration in the release medium was calculated as follows:

$$
\mathrm{H}_{2} \mathrm{O}_{2}[\mathrm{mM}]=\frac{\text { Absorbance }-0.0724}{0.1777} .
$$

Considering that this is the $\mathrm{H}_{2} \mathrm{O}_{2}$ concentration released by $200 \mu \mathrm{L}$ hydrogel in $800 \mu \mathrm{L}$ release medium, $\mathrm{H}_{2} \mathrm{O}_{2}$ amount (mmol) per volume hydrogel was calculated through the following equation:

$$
\frac{\mathrm{H}_{2} \mathrm{O}_{2}(\mathrm{mmol})}{\text { Volume }_{\text {hydrogel }}(\mathrm{L})}=\frac{\text { Absorbance }-0.0724}{0.1777} \times 4 \text {. }
$$

Each measurement was performed in quadruplicate $(n=4) . \mathrm{H}_{2} \mathrm{O}_{2}$ concentration values were reported in $\mathrm{mM}$, i.e., $m m o l \mathrm{H}_{2} \mathrm{O}_{2}$ released per unit volume (L) of hydrogel.

\section{Cytocompatibility Assessment of Hydrogels}

Cell lines including L929 (a murine fibroblast cell line) and $\mathrm{HaCaT}$ (a transformed human keratinocyte cell line) were obtained from DSMZ (German Collection of Microorganisms and Cell Cultures). L929 cells were maintained in RPMI 1640 cell culture medium with stable glutamine without glucose (P0418500, PAN Biotech, Germany), containing 10\% foetal bovine serum (FBS; PAN Biotech, Germany) under physiological culture conditions $\left(37^{\circ} \mathrm{C}, 5 \% \mathrm{CO}_{2}\right)$, and subcultured using $0.25 \%$ trypsin (Gibco, ThermoFisher Scientific, Germany). HaCaT cells were maintained in Dulbecco's modified Eagle's medium (DMEM) cell culture medium (PAN Biotech, Germany) containing 10\% FBS under physiological culture conditions $\left(37^{\circ} \mathrm{C}, 5 \% \mathrm{CO}_{2}\right)$, and subcultured using TrypLE ${ }^{\mathrm{TM}}$ Express (ThermoFisher Scientific, Germany).

Defined aliquots of cell suspensions for each cell type were used as follows: L929 [passage number (P) 7-P10] $0.7 \times 10^{5}$ cells/ well and $\mathrm{HaCaT}$ (P35-P37) $2.5 \times 10^{5}$ cells/well were pipetted into 24-well plates. Cells were incubated at $37^{\circ} \mathrm{C}$, with $5 \% \mathrm{CO}_{2}$ for $24 \mathrm{~h}$. Cell culture subconfluency and cell morphology were verified before exposing the cells to hydrogel samples. The culture medium was removed and replaced with fresh medium $(1 \mathrm{ml})$ before starting the assessment.

HB PEGDA/HA-SH 10.0-1.0 hydrogel samples $(30 \mu \mathrm{L})$ containing $\mathrm{G}$ and GO (Table 1) were freshly prepared under sterile conditions right before exposing them to the cell monolayer culture either through direct or indirect contact method (according DIN EN ISO 10993-5). For direct contact test, freshly prepared hydrogel samples (Table 1) were equilibrated in respective cell culture media for $10 \mathrm{~min}$ and placed in the center of the cell monolayer culture without making unnecessary movements of the specimens. Thus, each hydrogel sample of $\sim 5 \mathrm{~mm}$ diameter covered approx. 1/3rd growth area of the well surface of a 24 -well cell culture plate.

For indirect contact test, the hydrogel samples were exposed to L929 and HaCaT cells through 24-well Transwell ${ }^{\circledR}$ inserts (PET membrane, $1 \mu \mathrm{m}$ pore size, $6.5 \mathrm{~mm}$ diameter, Corning ${ }^{\circledR}$, Sarstedt, Germany), in a 24-well cell culture plate. Cell culture media volumes at apical $(250 \mu \mathrm{L})$ and basal sides $(800 \mu \mathrm{L})$ of inserts were maintained at the same level outside and inside the Transwell inserts. Cells on tissue culture treated polystyrene (TCPS) wells, without the addition of hydrogel samples, were used as "TCPS control wells," while cells treated with lysis solution (9\% Triton ${ }^{\circledR}$ $\mathrm{X}-100$ in water from Promega, Germany) served as "lysis control." Cells treated with HB PEGDA/HA-SH 10.0-1.0 hydrogels neither containing GO (0 U/L GO) nor glucose were also used as "polymer control". The well plate was then incubated at $37^{\circ} \mathrm{C}$, with $5 \% \mathrm{CO}_{2}$ for $24 \mathrm{~h}$.

After $24 \mathrm{~h}$, the supernatant culture medium and HB PEGDA/ HA-SH 10.0-1.0 specimens were carefully removed, and the 
CellTiter-Blue ${ }^{\circledR}$ assay (CTB, Promega, Germany) was performed for measuring the cell viability according to Promega's standard protocols (O’Brien et al., 2000).

To this aim, $400 \mu \mathrm{L}$ CTB reagent (enough to cover the surface of each well in a 24 -well plate) was pipetted into each well and left in incubation for $2 \mathrm{~h}$ at $37^{\circ} \mathrm{C}$ and $5 \% \mathrm{CO}_{2}$. The cell supernatant was transferred to black microtiter 96 -well plates. Fluorescence intensity was measured at excitation (Ex) of $560 \mathrm{~nm}$ and emission (Em) of $590 \mathrm{~nm}$ using a TECAN microplate reader Infinite ${ }^{\circledR} 200$ PRO (Tecan, Switzerland).

\section{Morphological Analysis of Cells}

Changes in morphological appearance and visualization of live and dead L929 and HaCaT cells were evaluated after a culture time of $24 \mathrm{~h}$ using bright field and fluorescent microscopy (Olympus IX51, Germany). Fluorescent staining was performed through Live/Dead imaging (Live/Dead Cell Staining Kit II, Promokine, VWR, Germany) using calcein$\mathrm{AM}$ and ethidium homodimer III (EthD-III) to detect live (green-fluorescence for live cells by enzymatic conversion of nonfluorescent substrate calcein-AM, Ex/Em $\sim 495 \mathrm{~nm} /$ $\sim 515 \mathrm{~nm}$ ) and dead (red-fluorescence for dead cells upon binding to nucleic acid, Ex/Em $\sim 530 \mathrm{~nm} / \sim 635 \mathrm{~nm}$ ) cells.

\section{Antibacterial Activity}

Staphylococcus aureus (ATCC 29213), Staphylococcus epidermidis (ATCC 12228), Pseudomonas aeruginosa (ATCC 27853), Escherichia coli (ATCC 25922), and Acinetobacter baumannii (as some of the most relevant bacteria in infected wounds) were used to evaluate antibacterial activity of $\mathrm{H}_{2} \mathrm{O}_{2}$-releasing $\mathrm{HB}$ PEGDA/HA-SH 10.0/1.0 hydrogels containing different amounts of GO (25-500 U/L, Table 1; Supplementary Figure S1) and constant $2.5 \% \mathrm{w} / \mathrm{w}$ G. Additionally, resistant strains with most commonly found resistance phenotypes were also tested including methicillin-resistant Staphylococcus aureus (MRSA), methicillin-resistant Staphylococcus epidermidis (MRSE), VIM2-producing drug-resistant Pseudomonas aeruginosa (Verona integron-encoded metallo- (VIM-2) $\beta$-lactamases-producing multidrug-resistant $P$. aeruginosa) (Viedma et al., 2012), and KPC-2-producing drug-resistant Escherichia coli (Ben Tanfous et al., 2017). These clinically isolated and highly resistant gramnegative bacteria came from the state reference sample and database for gram-negative bacteria at the Department for Medical Microbiology, Ruhr-University Bochum. The discdiffusion test was performed for antimicrobial susceptibility testing according to EUCAST (European Committee on Antimicrobial Susceptibility Testing) guidelines (EUCAST 2016). Bacterial strains were revived and cultured on fresh Mueller-Hinton ( $\mathrm{MH})$ agar 1 day before testing. The wellisolated colonies were suspended in $0.9 \%$ normal saline and adjusted to McFarland 0.5 (Weinstein 2021). The inoculum was spread evenly over the entire surface of $\mathrm{MH}$ agar using a sterile cotton swab. The freshly prepared hydrogel samples $(30 \mu \mathrm{L})$, in the form of $\sim 5 \mathrm{~mm}$ diameter bead-shaped discs, were applied on the agar plate within $15 \mathrm{~min}$ of bacterial inoculation. The plates were then incubated at $37^{\circ} \mathrm{C}$ for $16-20 \mathrm{~h}$ (within $15 \mathrm{~min}$ of disc application). The zone of

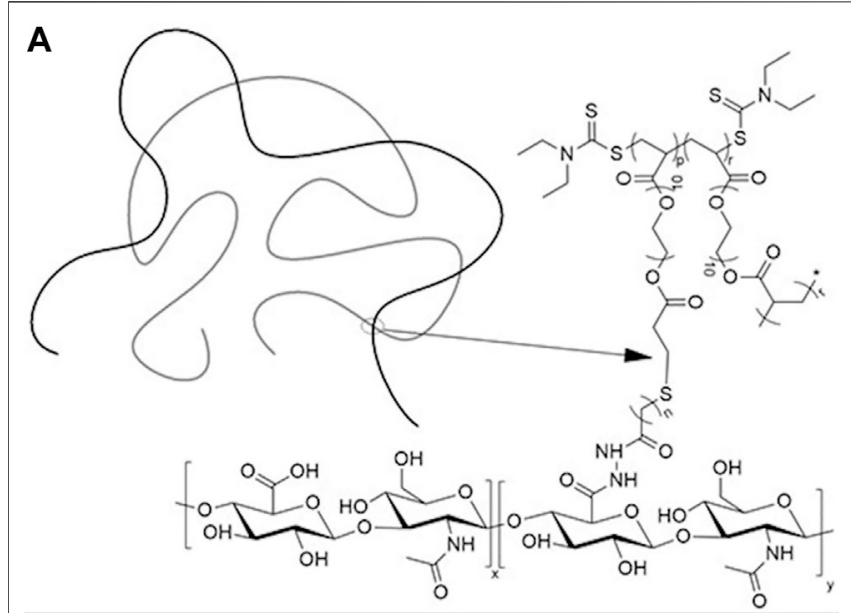

B

FIGURE 2 | (A): Schematic representation of the formation of a HB PEGDA/HA-SH hydrogel by thiol-ene cross-linking mechanism. (B): HB PEGDA/HA-SH 10.0-1.0 hydrogel beads (30 $\mu \mathrm{L})$ on the Teflon ${ }^{\mathrm{TM}}$ plate surface. (C): HB PEGDA/HA-SH 10.0-1.0 hydrogels $(200 \mu \mathrm{L})$ with cylindrical shape obtained by hydrogel cross-linking in a convenient mold. $(p=$ $0.45)(r=0.55)(n=2)(x=0.58)$ and $(y=0.42)$.

inhibition (ZOI, in $\mathrm{mm}$ ) was measured using a scale bar by reading the $\mathrm{MH}$ plates from the back against a dark background and zone edges were read at the point of complete inhibition.

\section{Statistical Analysis}

Data are represented as mean \pm standard deviation (SD) from two to four replicates depending on the analysis. Comparisons were made using one-way ANOVA or independent variable Student's $t$-test. Observations were considered to be significantly different for $p<0.05$ and highly significant for $p<0.01$.

All cell culture experiments and analyses of antibacterial activity were performed independently in duplicate $(N=2$, number of independent experiments) and four technical replicates were made and examined per experiment $(n=4)$.

\section{RESULTS}

\section{Chemical Characterization of HB PEGDA}

The HB PEGDA polymer was synthesized with weight average molecular weight $(\mathrm{Mw})$ of $16,656 \mathrm{Da}$, a number average molecular weight $(\mathrm{Mn})$ of $11,060 \mathrm{Da}$, a polydispersity index (PDI) of 1.5 , and a molar conversion of $32.5 \%$, as assessed by GPC analysis.

${ }^{1} \mathrm{H}$ NMR spectra (Supplementary Figure S4) allowed the analysis of the branched structure and amount of pendant acrylate groups in HB PEGDA. The pendant acrylate groups were identified through the three characteristic chemical shifts at 


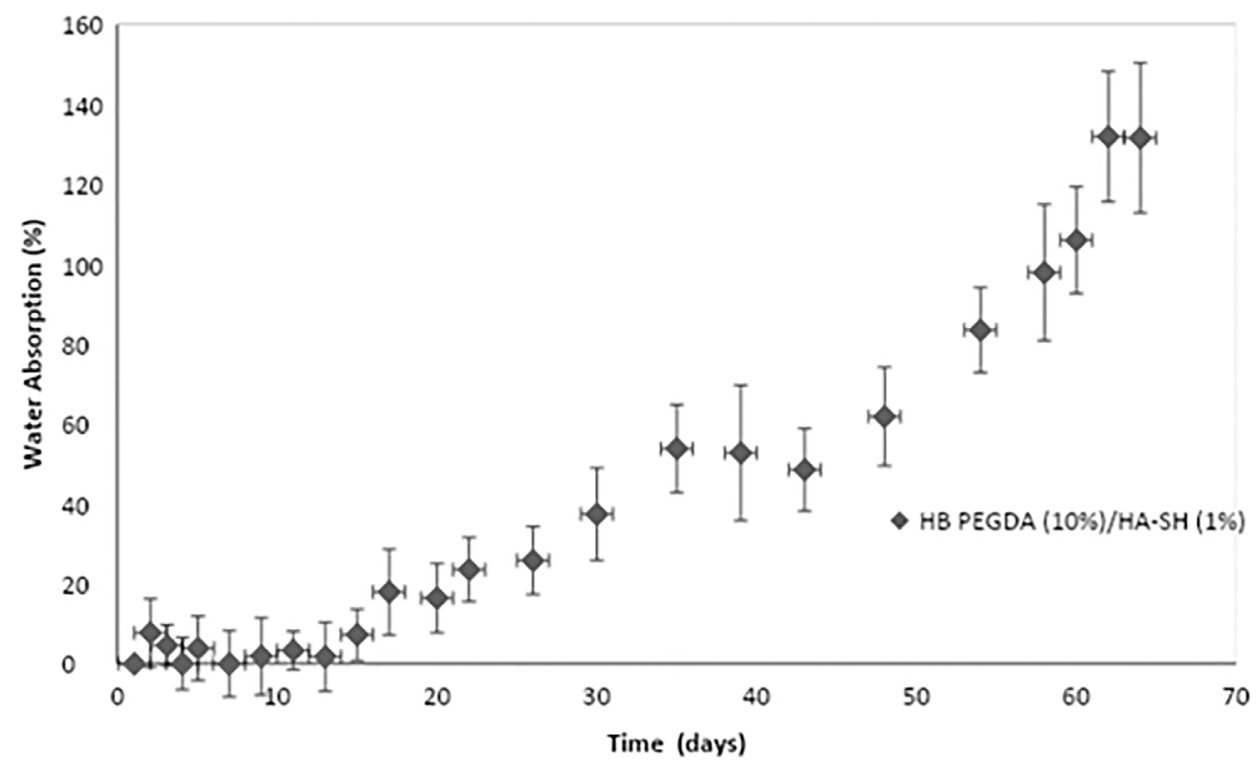

FIGURE 3 | Water uptake percentage of HB PEGDA/HASH 10.0-1.0 hydrogels as a function of time. Tests were performed using the HB PEGDA/HASH 10.0-1.0 hydrogel $(200 \mu \mathrm{L})$ in $2 \mathrm{ml}$ PBS solution at $37^{\circ} \mathrm{C}(n=4)$.

6.4-5.8 ppm, while PEG groups were identified through the chemical shifts at $4.34-3.95 \mathrm{ppm}$. Vinyl ratio was measured to be $57 \mathrm{~mol} \%$ with a vinyl content of $0.99 \mathrm{mmol}$ vinyl groups/g polymer. On the other hand, branching ratio was $43 \mathrm{~mol} \%$.

\section{HB PEGDA/HA-SH 10.0-1.0 Hydrogels: Formation Mechanism and Gelation Time}

The HB PEGDA/HA-SH 10.0-1.0 hydrogel formed through the reaction of acrylate groups of HB PEGDA with thiol groups of HA-SH via Michael addition reaction. Figure 2A schematically illustrates HB PEGDA and HA-SH cross-linking while Figures 2B,C show photos of HB PEGDA/HA-SH 10.0-1.0 hydrogels with different shapes. A volume of $30 \mu \mathrm{L}$ HB PEGDA/HA-SH 10.0-1.0 solution poured onto a hydrophobic Teflon ${ }^{\mathrm{TM}}$ plate surface formed hydrogel beads with $\sim 5 \mathrm{~mm}$ size at their bottom side (Figure 2B). HB PEGDA/HA-SH 10.0-1.0 hydrogels with $200 \mu \mathrm{L}$ volume and cylindrical shape were also formed using convenient molds (Figure 2C). The tube inverting test showed that HB PEGDA/HA-SH 10.0-1.0 hydrogels (with total volume of $1 \mathrm{ml}$ ) have an average gelation time of $63 \mathrm{~s}$.

\section{Water Uptake of HB PEGDA/HA-SH 10.0-1.0 Hydrogels}

Figure 3 shows water uptake percentage as a function of time for $\mathrm{HB}$ PEGDA/HA-SH $10.0-1.0$ hydrogels $(200 \mu \mathrm{L})$. In the first 2 weeks, absorbed water was less than $10 \%$ of hydrogel initial mass. After 14 days, water uptake percentage tended to increase as a function of time. However, HB PEGDA/HA-SH 10.0-1.0 hydrogel did not dissolve up to 64 days, reaching a water uptake percentage of $\sim 130 \%$.

\section{Hydrogen Peroxide Release From HB PEGDA/HA-SH 10.0-1.0 Hydrogels}

The in situ production and release of hydrogen peroxide from $\mathrm{HB}$ PEGDA/HA-SH 10.0-1.0 hydrogels (with $200 \mu \mathrm{L}$ volume) with varying $\mathrm{GO}$ concentrations from 25 to $500 \mathrm{U} / \mathrm{L}$ and constant $\mathrm{G}$ amount $(2.5 \% \mathrm{w} / \mathrm{w})$ (Table 1) was quantified over $24 \mathrm{~h}$ (Figure 4).

The amount of in situ released hydrogen peroxide increased continuously and significantly from $1.4 \pm 0.2$ to $10.8 \pm 1.4 \mathrm{mmol}$ per L hydrogel as a function of GO concentration (from 25 to $250 \mathrm{U} / \mathrm{L})$. By further increasing the amount of GO to reach $500 \mathrm{U} / \mathrm{L}$ activity, no further increase in the amount of in situ released hydrogen peroxide was measured. In fact, the $\mathrm{H}_{2} \mathrm{O}_{2}$ released from the hydrogel HB PEGDA/HA-SH 10.0-1.0 with $500 \mathrm{U} / \mathrm{L} \mathrm{GO}$ and $2.5 \% \mathrm{w} / \mathrm{w} \mathrm{G}$ was $11.2 \pm 0.7 \mathrm{mmol}$ per L hydrogel, which was a nonsignificantly different amount with respect to what released from the hydrogel with $250 \mathrm{U} / \mathrm{L}$ GO and $2.5 \% \mathrm{w} / \mathrm{w}$ $\mathrm{G}(p<0.001)$.

\section{Cytotoxicity Analysis}

Direct and Indirect Contact Test With L929 Fibroblasts

In the direct contact method with L929 cells, CTB assay results showed a decrease in cell viability with increasing GO amount, due to progressively higher $\mathrm{H}_{2} \mathrm{O}_{2}$ release (Figure 5A). The same type of hydrogel samples were also exposed to L929 cells via an indirect contact test. The viability of L929 cells (Figure 5B) was higher in indirect assays ( $75-83 \%)$-with cells exposed to the $\mathrm{H}_{2} \mathrm{O}_{2}$ amount released from hydrogel samples-than in direct assays $(\sim 37-100 \%)$ - with cells in contact with $\mathrm{H}_{2} \mathrm{O}_{2}$-releasing hydrogels (Figure 5A). 


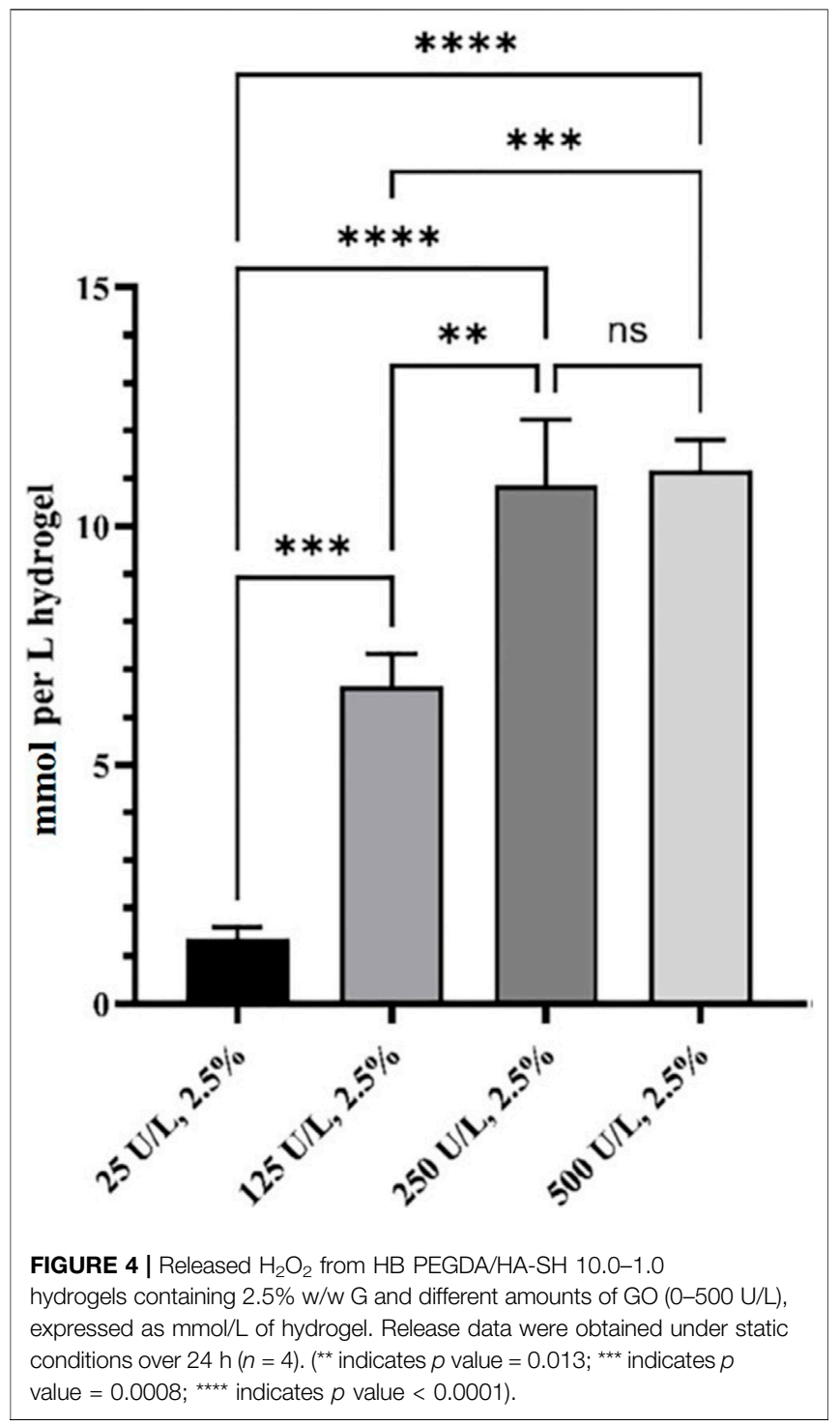

\section{Direct and Indirect Contact Test With HaCaT Keratinocytes}

$\mathrm{HaCaT}$ cells in direct contact with hydrogels containing GO concentrations from 25 to $250 \mathrm{U} / \mathrm{L}$ showed similar viability to control cells. However, the viability of $\mathrm{HaCaT}$ cells in contact with hydrogels with GO concentration of $500 \mathrm{U} / \mathrm{L}$ decreased to approximately $80 \%$ with respect to control cells (Figure 6A). In indirect tests, the viability of $\mathrm{HaCaT}$ cells exposed to eluates from HB PEGDA/HA-SH 10.0-1.0 hydrogels with different GO concentrations was similar to control cells (Figure 6B).

\section{Analysis of L929 and HaCaT Cell Morphology in Direct Contact Assays Direct Contact Test With L929 Fibroblasts}

On TCPS, after an incubation period of $24 \mathrm{~h}$, the L929 fibroblasts showed a typical spread morphology with only a few rounded cell bodies that were either in division (in pairs) or apoptotic (isolated) (Supplementary Figure S5A). In the lysis control, significantly few cell bodies were seen compared to those on the TCPS surface, which were also more separated from each other and had fewer spread cell bodies (reduced nucleus-plasma relation) with mostly roundish morphology. Morphology was similar for cells in contact with control hydrogel samples (not containing GO and G), hydrogels containing 25-125 U/L GO at constant $\mathrm{G}$ content and control TCPS. In the case of HB PEGDA/ HA-SH 10.0-1.0 sample with 250 U/L GO, most L929 fibroblasts showed similar morphology to TCPS controls; however, a few less densely packed cells with roundish morphology were also detected. Finally, in the case of HB PEGDA/HA-SH 10.0-1.0 sample with $500 \mathrm{U} / \mathrm{L}$ GO significantly fewer adherent cells were observed, and they almost exclusively exhibited a round morphology similar to those in the lysis control (Supplementary Figure S5A).

Live/dead assays served as evidence for almost $100 \%$ viability of L929 fibroblasts after $24 \mathrm{~h}$ cultivation on the control TCPS surface. Indeed, green-fluorescence results from the conversion of

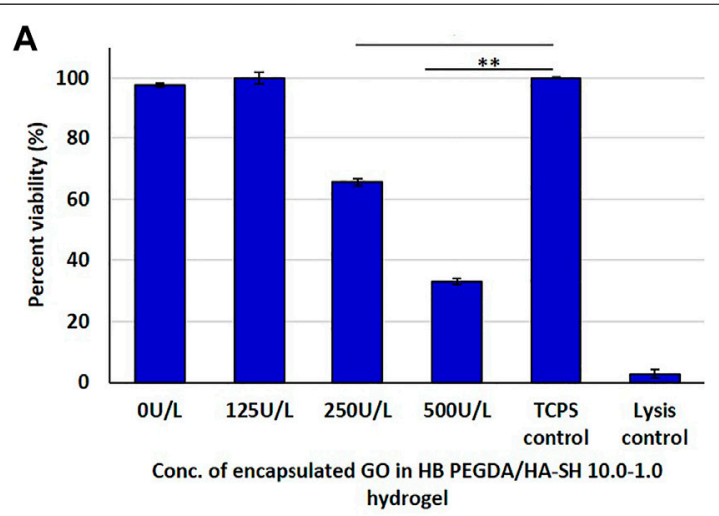

\section{B}

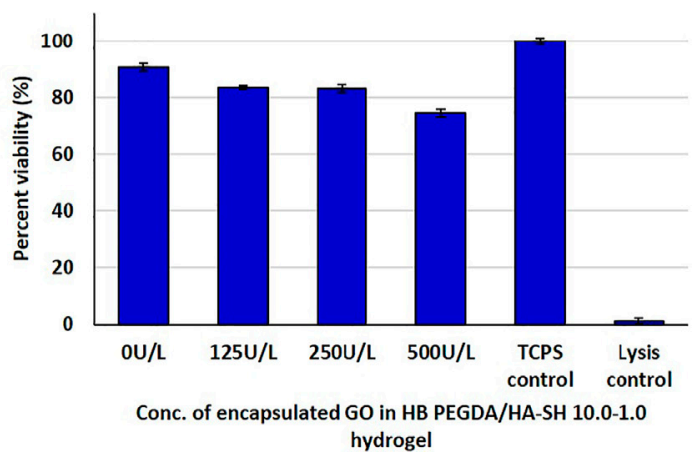

FIGURE 5 | Post $24 \mathrm{~h}$ cell viability data of L929 cells interacting with $\mathrm{H}_{2} \mathrm{O}_{2}$-releasing HB PEGDA/HA-SH 10.0-1.0 hydrogels containing different amounts of GO (25-500 U/L) and constant $\mathrm{G}$ amount (2.5\% w/w) using the quantitative CTB assay: (A) direct contact: $250 \mathrm{U} / \mathrm{L}$ and TCPS control ( ${ }^{*}$ indicates $p$ value $\left.=0.0006\right) ; 500 \mathrm{U} / \mathrm{L}$ and TCPS control ( ${ }^{* *}$ indicates $p$ value $\left.=0.0001\right)$; $\mathbf{( B )}$ indirect contact tests. 

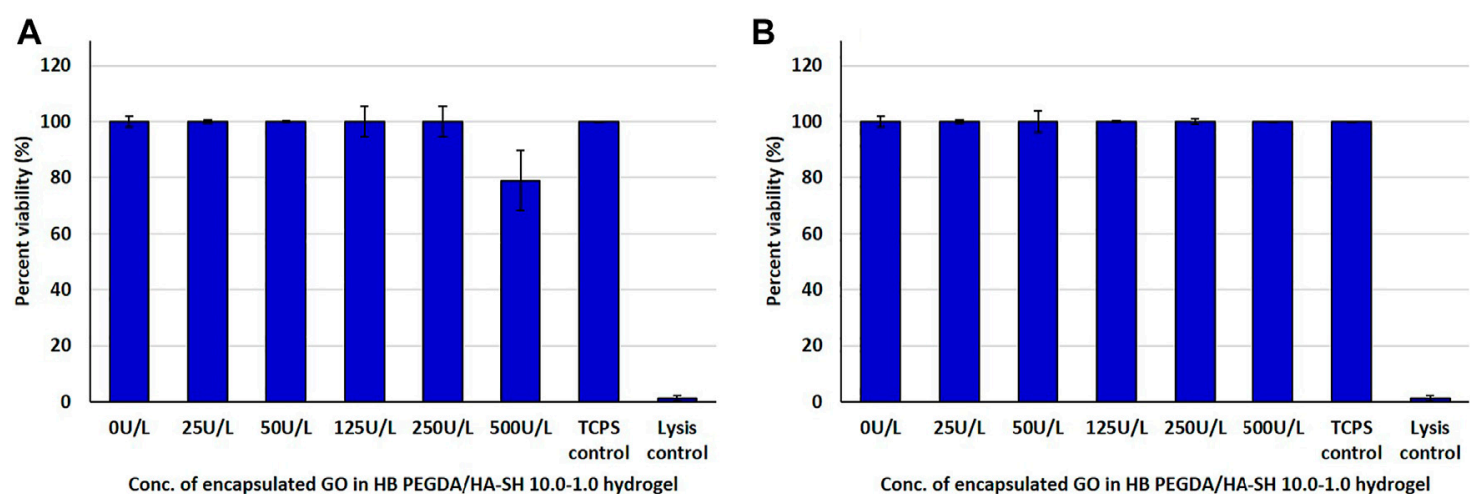

FIGURE 6 |Post 24 h cell viability data of $\mathrm{HaCaT}$ cells interacting with $\mathrm{H}_{2} \mathrm{O}_{2}$-releasing $\mathrm{HB}$ PEGDA/HA-SH 10.0-1.0 hydrogels containing different amounts of GO (25-500 U/L) and constant $\mathrm{G}$ amount $(2.5 \% \mathrm{w} / \mathrm{w})$ using the quantitative CTB assay: (A) direct contact and (B) indirect contact tests.

calcein-AM to calcein by esterase activity in viable cells. In contrast, only red-fluorescent avital cells were detected after treatment with Triton ${ }^{\circledR}$ X-100 (lysis control) (Supplementary Figure S5B). If the cell membrane integrity is disturbed or becomes porous and cells die, the intercalation dye EthD-III can penetrate the cells, enter their nucleus, and interact with their DNA. The Viability of L929 fibroblasts in contact with HB PEGDA/HA-SH 10.0-1.0 control hydrogel and TCPS controls was similar, showing rare red-fluorescent avital cells. However, L929 fibroblasts were slightly less close together than in control samples in some areas of the representative images. Similar results were obtained for cells in contact with HB PEGDA/HA-SH 10.0-1.0 hydrogel samples containing 25-50 U/L GO at constant G loading. On the contrary, only a few L929 fibroblasts in contact with hydrogel samples with $125 \mathrm{U} / \mathrm{L}$ GO activities showed prevalent green-fluorescent staining and normal size, while most cells showed reduced size and copresence of both staining. Finally, rare green-fluorescent cells were observed in contact with samples with $250 \mathrm{U} / \mathrm{L}$ GO activities, while most areas showed cells with double staining. When the amount of GO was further increased to $500 \mathrm{U} / \mathrm{L}$, the removal of the hydrogel sample, the rinsing step and the staining showed a significantly reduced number of cells, with approximately equal number of vital and avital cells (Supplementary Figure S5B).

\section{Direct Contact Test With HaCaT Keratinocytes}

HaCaT keratinocytes showed typical spread morphology on TCPS controls after an incubation period of $24 \mathrm{~h}$ (Supplementary Figure S6A). A confluent monolayer of human $\mathrm{HaCaT}$ keratinocytes was observed, with relatively uniform nucleus-plasma ratio, forming a relatively uniform, hexagonal pattern in their entirety. Each cell was in very close contact with six neighboring cells. In the case of HaCaT cells treated with Triton ${ }^{\circledR}$ X-100, fewer cells remained on TCPS plates, separated from each other, showing clearly shrunken cell bodies. In contrast, the morphology of HaCaT keratinocytes in contact with control hydrogels and hydrogels with 25-250 U/L GO and constant $\mathrm{G}$ amount was similar to that of cells on control TCPS plates. On the other hand, only fewer adherent cells with the typical HaCaT morphology were observed after the contact with hydrogels containing 500 U/L GO (Supplementary Figure S6A).

Live/dead fluorescence staining confirmed viability of $\mathrm{HaCaT}$ cells in contact with hydrogels containing up to $250 \mathrm{U} /$ L GO. In contrast, many attached, but avital cells were observed in the case of $\mathrm{HaCaT}$ cells in contact with hydrogels containing up to 500 U/L GO (Supplementary Figure S6B).

\section{Antibacterial Testing}

The antimicrobial activity or efficacy of the novel honey-mimetic $\mathrm{H}_{2} \mathrm{O}_{2}$-releasing $\mathrm{HB}$ PEGDA/HA-SH 10.0-1.0 hydrogels containing different amounts of GO (25-500 U/L) and constant G amount $(2.5 \% \mathrm{w} / \mathrm{w})$ was investigated against a variety of gram-positive (Figure 7) and gram-negative (Figure 8) bacteria that have significant clinical importance in wound colonization and infection.

In addition to Staphylococcus aureus (ATCC 29213), Staphylococcus epidermidis (ATCC 12228), Pseudomonas aeruginosa (ATCC 27853), Escherichia coli (ATCC 25922), Acinetobacter baumannii (some of the most relevant bacteria in infected wounds), and some of the most commonly found resistance phenotypes, including methicillin-resistant Staphylococcus aureus (MRSA), methicillin-resistant Staphylococcus epidermidis (MRSE), VIM-2-producing drug-resistant Pseudomonas aeruginosa, and KPC-2-producing drug-resistant Escherichia coli, were also tested.

All gram-positive bacteria types showed susceptibility (appearance of an inhibition zone, ZOI) to the in situ released hydrogen peroxide from the HB PEGDA/HA-SH 10.0-1.0 hydrogel containing the lowest amount of GO (25 U/L). As the amount of GO into the hydrogels increased (50-500 U/L), the ZOI values also increased continuously (Figure 7). This means, in detail, that for the sensitive $S$. aureus strain, for example, there was a highly significant increase in the ZOI with an increase in GO activity by a factor of five from 25 to $125 \mathrm{U} / \mathrm{L}(p<0.01)$. While for all other gram-positive strains, highly significant ZOI enlargements were already shown with a doubling of GO activity from 25 to $50 \mathrm{U} / \mathrm{L}$. A further increase in GO activity from 50 to $125 \mathrm{U} / \mathrm{L}$ for the gram-positive strains $S$. epidermidis and MRSA only showed a tendency to increase the 

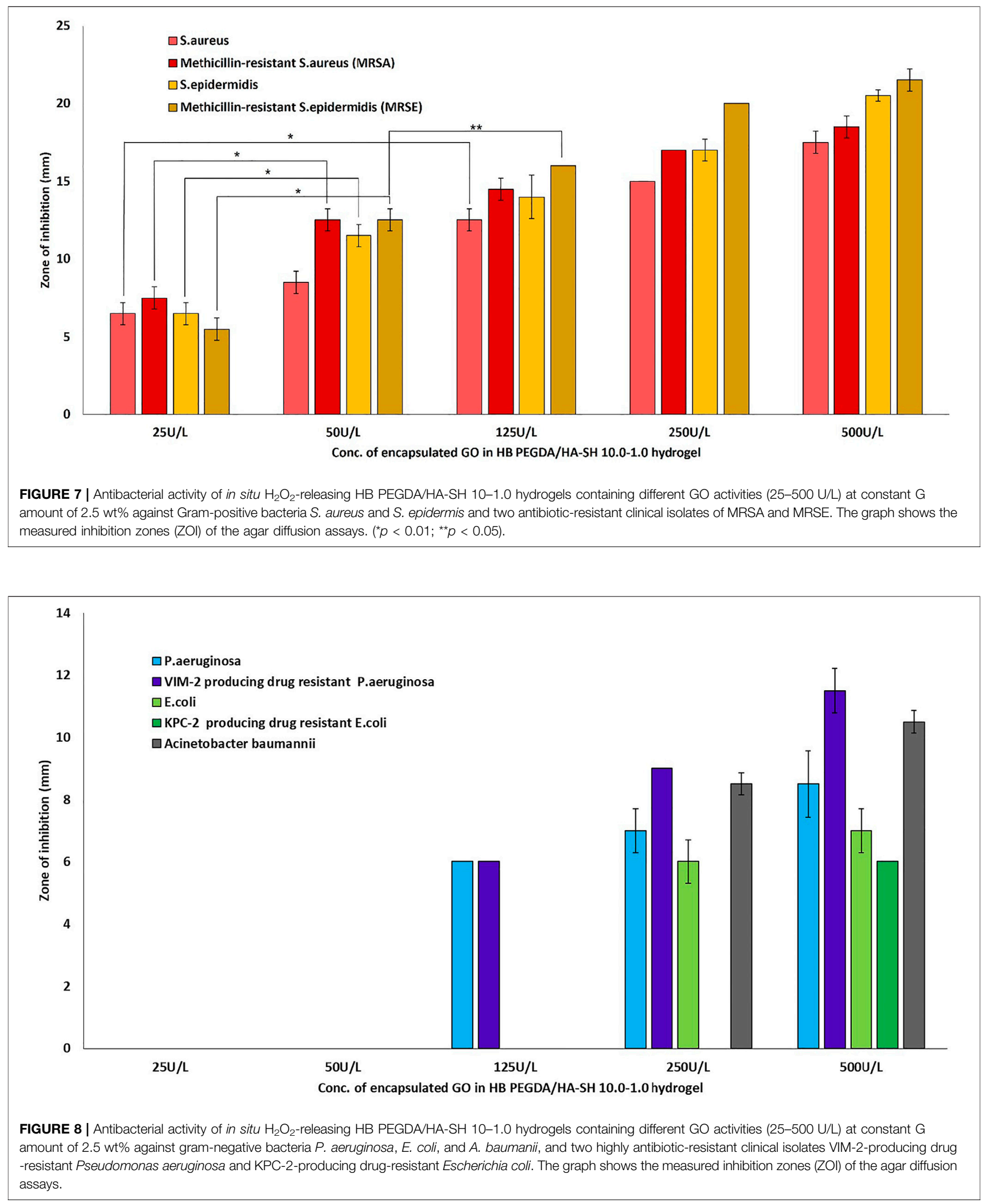
ZOI, but this was not significant. A slightly significant increase in ZOI could only be measured for MRSE $(p<0.05)$.

The two tested $P$. aeruginosa strains, the antibiotic-sensitive strain and the highly resistant strain VIM-2-producing drugresistant Pseudomonas aeruginosa, were only susceptible to the hydrogen peroxide amount released from hydrogels with GO activity of $125 \mathrm{U} / \mathrm{L}$. Although a tendency for ZOI to increase was measured for both strains when GO activity was increased from 125 to $250-500 \mathrm{U} / \mathrm{L}$, these were not statistically significant (Figure 8). For the two antibiotic-sensitive strains E. coli and A. baumanii, a ZOI was only shown from hydrogels with a GO activity of $250 \mathrm{U} / \mathrm{L}$, while for the highly resistant KPC-2producing drug-resistant Escherichia coli, the ZOI was only shown for hydrogels with a GO activity of $500 \mathrm{U} / \mathrm{L}$ (Figure 8).

\section{DISCUSSION}

In this work, new antimicrobial hydrogels capable of releasing hydrogen peroxide in situ through a honey-inspired approach were designed, to be used as injectable or preformed hydrogels for future applications in the treatment of bacterially colonized or infected wounds. The hydrogels consisted of a chemically cross-linked polymeric network formed by the reaction of HB PEGDA and HA-SH components. HB PEGDA was a synthesized hyperbranched polymer (Figure 1) with a $\mathrm{Mw}$ of $16,656 \mathrm{Da}$, PDI of 1.5 , vinyl ratio of $57 \mathrm{~mol} \%$, and a branching ratio of 43 mol\% (Supplementary Figure S4). Thus the vinyl ratio was in the $40-60 \mathrm{~mol} \%$ range typically reported for hyperbranched polymers suggesting a high degree of branching (Wang et al., 2015). On the other hand, the relatively high vinyl content (43 mol $\%$ ) is beneficial for faster polymer cross-linking. The herein used HA-SH was produced and purchased from Blafar Ltd.

The HB PEGDA/HA-SH 10.0-1.0 hydrogel formed through reaction of acrylate groups of HB PEGDA and thiol groups of HA-SH via Michael addition reaction. Michael addition works by the weak sulfur-hydrogen bonds of HA-SH reacting with the electron-deficient acrylate groups in the HB PEGDA (Nair et al., 2014) (Figure 2A). The ability to achieve quantitative conversion without by-product formation, even under dilute conditions, makes thiol-Michael addition click reaction particularly suitable for biomedical applications (Nair et al., 2014).

In this work, one HB PEGDA/HA-SH hydrogel composition was explored for the design of injectable hydrogels for in situ formation and release of hydrogen peroxide: HB PEGDA/HA-SH 10.0/1.0 hydrogel, based on HB PEGDA/HA-SH blend with 91/ $9 \mathrm{w} / \mathrm{w}$ relative composition, and having $11 \% \mathrm{w}_{\text {blend }} / \mathrm{v}_{\text {water }}$ overall hydrogel concentration. This hydrogel showed a gelation time of around $60 \mathrm{~s}$ which ensured injectability. Proof-of-concept hydrogels with different and reproducible shapes were obtained, including hydrogel droplets on Teflon substrates and cylindrical hydrogels through molding (Figures 2B,C). Water uptake tests, performed on small volumes of hydrogels $(200 \mu \mathrm{L})$ showed their limited swelling ability in the first 2 weeks of incubation in PBS and their resistance to loss of shape up to 64 days (Figure 3). Despite this observation, similar hydrogel systems composed of cross-links of PEG-diacrylates or PEG-diacrylamides with sulfhydryl group- containing peptides are known to exhibit hydrolytic instability not only at $\mathrm{pH} \mathrm{8,} \mathrm{but} \mathrm{also} \mathrm{more} \mathrm{slowly} \mathrm{at} \mathrm{pH}$ 7.4. Hydrolysis kinetics show that the hydrolysis half-life is a few days (Elbert and Hubbell, 2001). In this case, it is not the thioether group formed by Michael addition (click reaction) that is hydrolytically unstable, but the ester bond or amide bond located in the neighboring position with the amide bond being more stable than the ester bond. Other authors point out that the stability of such cross-links is strongly dependent on the neighboring groups and on the overall molecular structure of such hydrogel networks (Rydholm et al., 2011; Pérez-Madrigal et al., 2020). In the future, the biodegradability of the HB PEGDA/ HA-SH system presented here will need to be investigated for application times greater than $24 \mathrm{~h}$. Nevertheless, all the properties presented here are promising and ensure the possibility of longterm release of encapsulated drugs/molecules in case of drug delivery or long-term support of cells in case of cell delivery therapies. (Wechsler et al., 2019). Progressive increase in water uptake versus time is expected to enlarge hydrogel mesh radius increasing hydrogel permeability, favoring the release of drugs or the exchange of nutrients and metabolites, supporting cell viability in cell therapies, bioprinting applications, and other tissue engineering approaches (Richbourg et al., 2021). Indeed, previously, some of the coauthors employed HB PEGDA/HA$\mathrm{SH}$ hydrogels as injectable systems for adipose stem cell therapy to treat diabetic wounds, preclinically validated in mice (Xu et al., 2018). As a next step, in this work, the hydrogel was proposed as an injectable system for the in situ formation and release of the antimicrobial agent hydrogen peroxide. As the antimicrobial mechanism of honey mainly depends on GO enzyme and G, allowing the formation of hydrogen peroxide, varying GO amounts were encapsulated into HB PEGDA component, keeping a fixed $\mathrm{G}$ content in the HA-SH component. Hydrogen peroxide production, determined under static conditions for a period of $24 \mathrm{~h}$, increased as a function of GO concentration up to $250 \mathrm{U} / \mathrm{L}$ and then settled to an approximately constant value (10.8 \pm $1.4 \mathrm{mmol}$ per L hydrogel) (Figure 4). The amount of released $\mathrm{H}_{2} \mathrm{O}_{2}$ can be changed based on hydrogel volume (at fixed GO and $\mathrm{G}$ content) or by tuning GO content (at fixed G amount and hydrogel volume). A previous study by Loo et al. showed that daily topical application of $15 \mu \mathrm{L} \quad \mathrm{H}_{2} \mathrm{O}_{2}$ solution with varying concentrations $(10-166 \mathrm{mM})$ on skin wounds in C57/BL6 mice for overall 10 days caused different effects, from enhanced angiogenesis with $10 \mathrm{mM}$, i.e., $0.15 \mu \mathrm{mol} /$ wound, to wound closure retard with $166 \mathrm{mM}$, i.e., $2.5 \mu \mathrm{mol} /$ wound, (Loo et al., 2012).

A proper $\mathrm{GO}$ amount at constant $\mathrm{G}$ content should be selected to provide an antibacterial effect on a skin wound without causing simultaneous damage to dermal fibroblasts of the wound bed and to epidermal keratinocytes from wound edges. Therefore, initially in vitro investigations were performed in order to confirm the cytocompatibility of the HB PEGDA/HA-SH 10.0-1.0 hydrogel and to investigate the cytotoxic effect of the released amounts of hydrogen peroxide. Two internationally well-known fibroblast (L929) and epithelial (HaCaT) cell lines were used for the in vitro analysis, following DIN EN ISO 10993-5 standards. Furthermore, they represent typical starting cell lines for future investigations in the field of external wound treatment (Rajan et al., 2020; Ribeiro et al., 2020; De la Cruz-Concepción et al., 2021). 
Before investigating the antibacterial activity and efficacy of the in situ hydrogen peroxide-releasing HB PEGDA/HA-SH hydrogel samples on certain gram-positive and gram-negative bacteria, quantitative direct and indirect cytotoxicity analyses were performed by the CTB assay on L929 and HaCaT cultures. Both tests are part of DIN EN ISO 10993-5 standards. Direct cytotoxicity tests allow the analysis of the behavior of cells in contact with or close to $\mathrm{H}_{2} \mathrm{O}_{2}$-releasing $\mathrm{HB}$ PEGDA/HA-SH hydrogel. In this test, results are affected by the release of $\mathrm{H}_{2} \mathrm{O}_{2}$ and the swelling of the hydrogel and its interaction with the cells. However, the direct test cannot separate the cytotoxic effect due to released $\mathrm{H}_{2} \mathrm{O}_{2}$ amount from that due to the hydrogel composition or its acting as a physical barrier in the diffusion of nutrients and catabolites. In contrast, in the indirect cytotoxicity test, the HB PEGDA/HA-SH sample itself is not in contact with the cells, and only $\mathrm{H}_{2} \mathrm{O}_{2}$ released in the medium may affect cell cytotoxicity.

Direct contact of the L929 fibroblasts with the HB PEGDA/ HA-SH 10.0-1.0 hydrogels containing different amounts of GO (25-500 U/L) and constant $\mathrm{G}$ amount $(2.5 \% \mathrm{w} / \mathrm{w})$ showed a strong decrease in viability with increasing enzyme loading in the quantitative CTB assay (Figure 5A). In contrast, the indirect assay only showed a slight decrease in the viability of the fibroblasts with increasing GO amount (Figure 5B). L929 fibroblast viability decrease in the direct contact assay was probably due to an undersupply of nutrients and oxygen to the cells and additionally to the simultaneous $\mathrm{H}_{2} \mathrm{O}_{2}$ release and its accumulation below the hydrogel sample.

In contrast to fibroblasts, in direct tests, $\mathrm{HaCaT}$ keratinocytes showed no decrease in viability with increasing GO loading in the HB PEGDA/HA-SH 10.0-1.0 hydrogel, except for GO equal to $500 \mathrm{U} / \mathrm{L}$, showing nonsignificant decrease in viability (Figures 6A,B). As compared to L929 fibroblasts, HaCaT keratinocytes were resistant to $\mathrm{H}_{2} \mathrm{O}_{2}$-induced cytotoxicity. Such findings are in agreement with in vitro data discussed in the study by Lee et al. who also showed that HaCaT keratinocytes gave slightly higher viability values than L929 fibroblasts (Lee et al., 2017).

Cell morphology studies (in direct contact tests) showed analogous differences in sensitivity to oxidative stress by released $\mathrm{H}_{2} \mathrm{O}_{2}$ between $\mathrm{L} 929$ fibroblasts and $\mathrm{HaCaT}$ keratinocytes when considering the hydrogel samples with 250 and 500 U/L GO activity (Supplementary Figures S5A,B, S6A,B). In the case of L929 cells interaction with hydrogels containing $125 \mathrm{U} / \mathrm{L}$ GO, the CTB assay showed a cell viability of $100 \%$ compared to those in the TCPS control and almost equal to the unmodified HB PEGDA/HA-SH hydrogel (Figure 5A). The corresponding fluorescence microscopic image after $\mathrm{L} / \mathrm{D}$ staining suggested a large number of L929 cells showing esterase metabolism and converting calcein-AM into calcein (green fluorescence), and the copresence of cells with compromised membrane integrity allowing the intercalating dye EthD-III to penetrate L929 cells and interact with their DNA (red fluorescence) (Supplementary Figure S5B, 125 U/L). This finding suggested that the evaluation of real cytotoxic data is not sufficient by performing only one assay or measurement principle.

Figure 7 demonstrates the antibacterial activity of in situ $\mathrm{H}_{2} \mathrm{O}_{2}$ releasing HB PEGDA/HA-SH 10-1.0 hydrogels containing different
GO activities (25-500 U/L) at constant $\mathrm{G}$ amount of $2.5 \mathrm{wt} \%$ against the gram-positive bacteria $S$. aureus and $S$. epidermis and two antibiotic resistant clinical isolates of MRSA and MRSE. In agar diffusion assays, ZOI-measured on hydrogel samples with the same volume $(30 \mu \mathrm{L})$ as the ones used for cytocompatibility assays-increased with increasing the GO concentration and was also displayed in the case of methicillin-resistant gram-positive bacteria. However, in contrast to gram-positive bacteria, gramnegative bacteria $P$. aeruginosa and VIM-2-producing drugresistant $P$. aeruginosa only showed ZOI at GO activity $\geq 125 \mathrm{U} / \mathrm{L}$ (Figure 8). For an antibiotic-sensitive E. coli and A. baumanii strain, the ZOI was only measured in the case of hydrogels with GO activity of $250 \mathrm{U} / \mathrm{L}$. In addition, ZOIs of the hydrogel samples with higher GO activities were large for gram-positive compared to gramnegative bacteria, indicating that the gram-positive bacteria are much more susceptible to oxidative stress. There are various reasons for this significant difference between the measured ZOI for gram-positive compared to the gram-negative bacteria. One reason is the different structural composition of gram-positive and gram-negative bacteria: gram-negative bacteria have an outer lipid-based membrane that is additionally decorated with lipopolysaccharides (LPS), while gram-positive bacteria lack this outer lipid bilayer. The peptidoglycans of the outer layer of the gram-positive bacteria have been reported to be significantly more sensitive to oxidation (Rapacka-Zdończyk et al., 2021). In addition, Lee et al. showed that the LPS of the gram-negative bacteria have an antioxidant effect and thus eliminate part of the hydrogen peroxide produced and released in situ (Lee et al., 2017).

\section{CONCLUSION}

In summary, an in situ producing $\mathrm{H}_{2} \mathrm{O}_{2}$-PEGDA/HA-SH 10-1.0 hydrogel was developed that can be used as a drug-free antibacterial injectable hydrogel for the treatment of infected wounds. Based on the data so far, it can be said that GO activities of $125 \mathrm{U} / \mathrm{L}$ resulted in acceptable ZOIs for the gram-positive bacterial strains without affecting the viability of the fibroblasts too much within $24 \mathrm{~h}$. This is a good indication that the hydrogel can be used for the treatment of infected wounds.

It was also shown that the keratinocytes were significantly less sensitive. To the extent possible based on this initial in vitro study, this honey-mimetic antibacterial hydrogel could also be used as a complementary system with some gram-negative bacteria such as $P$. aeruginosa and VIM-2-producing drugresistant $P$. aeruginosa. Here, further studies with bacterially colonized $3 \mathrm{D}$ skin equivalents and over longer cultivation periods are required to assess the effective extent of cytotoxicity of the hydrogen peroxide released from this hydrogel. It is expected that the use of alternative antimicrobial solutions to antibiotics will help combat antimicrobial resistance. Considering its rapid formation, ability to produce $\mathrm{H}_{2} \mathrm{O}_{2}$ continuously, and antibacterial activity against susceptible and methicillin-resistant grampositive bacteria while being cytocompatible for eukaryotic cells, this type of hydrogel represents a promising material for wound dressings and deserves further investigation. 


\section{DATA AVAILABILITY STATEMENT}

The raw data supporting the conclusion of this article will be made available by the authors, without undue reservation.

\section{AUTHOR CONTRIBUTIONS}

JV synthesized HB PEGDA, prepared the hydrogels, and characterized them for their physicochemical properties. AI characterized hydrogels extensively for their biocompatibility and antimicrobial properties. IC supervised JV experimental activity at Politecnico di Torino. AS, SM, UG, HT, and WW supervised JV during her secondment period at Blafar Ltd. and WW Research Group. Additionally, the whole team was responsible for the development, production, and characterization of medical grade HA-SH. LM isolated, expanded, and characterized the used bacterial strains and supervised AI's microbiological experimental activity during her secondment period at Jochen Salber's lab. All cytocompatibility experiments were carried out at JS's lab. VC, WW, GC, and UG were JV supervisors during her doctorate. VC and JS were AI supervisors during her doctorate. GC, WW, and JS were unit coordinators, while HT was one of the industrial partners in the HyMedPoly project. The manuscript was written through main contribution by VC and JS with further help by the authors, particularly IC, AI, and JV. VC and JS cosupervised the work as senior authors. All authors have given approval to the final version of the manuscript.

\section{FUNDING}

This work has received funding from the European Union's Horizon 2020 research and innovation programme under the Marie Sklodowska-Curie actions (HyMedPoly project; Grant Agreement No. 643050).

\section{REFERENCES}

Abuharfeil, N., Al-Oran, R., and Abo-Shehada, M. (1999). The Effect of Bee Honey on the Proliferative Activity of Human B-And T-Lymphocytes and the Activity of Phagocytes. Food Agric. Immunol. 11 (2), 169-177. doi:10.1080/ 09540109999843

Albaridi, N. A. (2019). Antibacterial Potency of Honey. Int. J. Microbiol. 2019, 2464507. doi: $10.1155 / 2019 / 2464507$

Arul, V., Masilamoni, J. G., Jesudason, E. P., Jaji, P. J., Inayathullah, M., Dicky John, D. G., et al. (2012). Glucose Oxidase Incorporated Collagen Matrices for Dermal Wound Repair in Diabetic Rat Models: A Biochemical Study. J. Biomater. Appl. 26 (8), 917-938. doi:10.1177/0885328210390402

Ballal, M., Bairy, I., Shenoy, V., and Shivananda, P. (2012). Honey as an Antimicrobial Agent against Pseudomonas Aeruginosa Isolated from Infected Wounds. J. Glob. Infect Dis. 4 (2), 102-105. doi:10.4103/0974777X.96770

Ben Tanfous, F., Alonso, C. A., Achour, W., Ruiz-Ripa, L., Torres, C., and Ben Hassen, A. (2017). First Description of KPC-2-Producing Escherichia coli and ST15 OXA-48-Positive Klebsiella pneumoniae in Tunisia. Microb. Drug. Resist. 23 (3), 365-375. doi:10.1089/mdr.2016.0090

Bogdanov, S. (1997). Nature and Origin of the Antibacterial Substances in Honey. LWT - Food Sci. Technol. 30 (7), 748-753. doi:10.1006/fstl.1997.0259

\section{ACKNOWLEDGMENTS}

Contribution from the European Union's Horizon 2020 research and innovation programme under the Marie Sklodowska-Curie actions (HyMedPoly project; Grant Agreement No. 643050) is acknowledged. The authors thank some members of Wenxin Wang's research group, namely, Luca Pierruci, Sofia Kivotidi, Qian Xu, Xiao Lin Li, Hind Eddahani, and Manon Venet, for their kind help.

\section{SUPPLEMENTARY MATERIAL}

The Supplementary Material for this article can be found online at: https:/www.frontiersin.org/articles/10.3389/fbioe.2021.742135/ full\#supplementary-material

Supplementary Figure 1| Preparation of $\mathrm{H}_{2} \mathrm{O}_{2}$-releasing 10\% HB-PEGDA $1 \% \mathrm{HA}$ $\mathrm{SH}$ hydrogel solution.

Supplementary Figure 2| Colorimetric measurement of in situ generated $\mathrm{H}_{2} \mathrm{O}_{2}$.

Supplementary Figure 3 | Calibration curve of $\mathrm{H}_{2} \mathrm{O}_{2}$ obtained by the pertitanic acid assay.

Supplementary Figure $4 \mid{ }^{1} \mathrm{H}$ NMR spectrum of synthesized HB PEGDA (Mw $16,656 \mathrm{Da})$.

Supplementary Figure 5 | (A) Bright-field micrographs of L929 cells after $24 \mathrm{~h}$ interaction with $\mathrm{H}_{2} \mathrm{O}_{2}$-releasing HB PEGDA $\mathrm{HA}-\mathrm{SH}$ 10.0-1.0 hydrogels containing different amounts of $\mathrm{GO}(25-500 \mathrm{U} / \mathrm{L})$ and constant $\mathrm{G}$ amount $(2.5 \% \mathrm{~W} / \mathrm{w})$ versus controls (TCPS and lysis controls). (B) Fluorescent micrographs of Live/Deadstained L929 cells after $24 \mathrm{~h}$ interaction with $\mathrm{H}_{2} \mathrm{O}_{2}$-releasing HB PEGDA $\mathrm{HA}$-SH 10.0-1.0 hydrogels containing different amounts of GO (25-500 U/L) and constant $\mathrm{G}$ amount $(2.5 \% \mathrm{~W} / \mathrm{W})$ versus controls (TCPS and lysis controls).

Supplementary Figure 6 | (A) Bright-field micrographs of $\mathrm{HaCaT}$ cells after $24 \mathrm{~h}$ interaction with $\mathrm{H}_{2} \mathrm{O}_{2}$-releasing $\mathrm{HB}$ PEGDA $\mathrm{HA}-\mathrm{SH}$ 10.0-1.0 hydrogels containing different amounts of $\mathrm{GO}(25-500 \mathrm{U} / \mathrm{L})$ and constant $\mathrm{G}$ amount $(2.5 \% \mathrm{~W} / \mathrm{W})$ versus controls (TCPS and lysis controls). (B) Fluorescent micrographs of Live/Deadstained $\mathrm{HaCaT}$ cells after $24 \mathrm{~h}$ interaction with $\mathrm{H}_{2} \mathrm{O}_{2}$-releasing HB PEGDA HA$\mathrm{SH}$ 10.0-1.0 hydrogels containing different amounts of GO (25-500 U/L) and constant $\mathrm{G}$ amount $(2.5 \% \mathrm{~W} / \mathrm{w}$ ) versus controls (TCPS and lysis controls).

Brimson, C. H., and Nigam, Y. (2013). The Role of Oxygen-Associated Therapies for the Healing of Chronic Wounds, Particularly in Patients with Diabetes. J. Eur. Acad. Dermatol. Venereol. 27 (4), 411-418. doi:10.1111/j.14683083.2012.04650.x

Cooke, J., Dryden, M., Patton, T., Brennan, J., and Barrett, J. (2015). The Antimicrobial Activity of Prototype Modified Honeys that Generate Reactive Oxygen Species (ROS) Hydrogen Peroxide. BMC Res. Notes 8 (1), 20-28. doi:10.1186/s13104-014-0960-4

Cooper, R. A., Molan, P. C., and Harding, K. G. (1999). Antibacterial Activity of Honey against Strains of Staphylococcus Aureus from Infected Wounds. J. $R$. Soc. Med. 92 (6), 283-285. doi:10.1177/014107689909200604

De la Cruz-Concepción, B., Espinoza-Rojo, M., Álvarez-Fitz, P., Illades-Aguiar, B., Acevedo-Quiroz, M., Zacapala-Gómez, A. E., et al. (2021). Cytotoxicity of Ficus Crocata Extract on Cervical Cancer Cells and Protective Effect against Hydrogen Peroxide-Induced Oxidative Stress in HaCaT Non-tumor Cells. Plants 10 (1), 183-194. doi:10.3390/plants10010183

Deshmukh, M., Singh, Y., Gunaseelan, S., Gao, D., Stein, S., and Sinko, P. J. (2010). Biodegradable Poly(Ethylene Glycol) Hydrogels Based on a Self-Elimination Degradation Mechanism. Biomaterials 31 (26), 6675-6684. doi:10.1016/ j.biomaterials.2010.05.021

Dong, Y., Saeed, A. O., Hassan, W., Keigher, C., Zheng, Y., Tai, H., et al. (2012). "One-step" Preparation of Thiol-Ene Clickable PEG-Based Thermoresponsive Hyperbranched Copolymer for In Situ Crosslinking 
Hybrid Hydrogel. Macromol. Rapid Commun. 33 (2), 120-126. doi:10.1002/ marc.201100534

Dong, Y., Qin, Y., Dubaa, M., Killion, J., Gao, Y., Zhao, T., et al. (2015). A Rapid Crosslinking Injectable Hydrogel for Stem Cell Delivery, from Multifunctional Hyperbranched Polymers via RAFT Homopolymerization of PEGDA. Polym. Chem. 6 (34), 6182-6192. doi:10.1039/c5py00678c

Dunnill, C., Patton, T., Brennan, J., Barrett, J., Dryden, M., Cooke, J., et al. (2017). Reactive Oxygen Species (ROS) and Wound Healing: The Functional Role of ROS and Emerging ROS-Modulating Technologies for Augmentation of the Healing Process. Int. Wound J. 14 (1), 89-96. doi:10.1111/iwj.12557

Eisenberg, G. (1943). Colorimetric Determination of Hydrogen Peroxide. Ind. Eng. Chem. Anal. Ed. 15 (5), 327-328. doi:10.1021/i560117a011

Elbert, D. L., and Hubbell, J. A. (2001). Conjugate Addition Reactions Combined with Free-Radical Cross-Linking for the Design of Materials for Tissue Engineering. Biomacromolecules 2 (2), 430-441. doi:10.1021/bm0056299

European Society of Clinical Microbiology and Infectious Diseases (2021). Disk Diffusion Method for Antimicrobial Susceptibility Testing. Antimicrobial Susceptibility Testing (EUCAST) Version 9.0, 1-22. Available at: http://www. eucast.org.

Kennedy, R., Ul Hassan, W., Tochwin, A., Zhao, T., Dong, Y., Wang, Q., et al. (2014). In Situ Formed Hybrid Hydrogels from PEG Based Multifunctional Hyperbranched Copolymers: A RAFT Approach. Polym. Chem. 5 (6), 1838-1842. doi:10.1039/c3py01513k

Lee, Y., Choi, K.-H., Park, K. M., Lee, J.-M., Park, B. J., and Park, K. D. (2017). In Situ Forming and H2O2-Releasing Hydrogels for Treatment of Drug-Resistant Bacterial Infections. ACS Appl. Mater. Inter. 9 (20), 16890-16899. doi:10.1021/ acsami. $7 \mathrm{~b} 03870$

Loebel, C., Rodell, C. B., Chen, M. H., and Burdick, J. A. (2017). Shear-Thinning and Self-Healing Hydrogels as Injectable Therapeutics and for 3D-Printing. Nat. Protoc. 12 (8), 1521-1541. doi:10.1038/nprot.2017.053

Loo, A. E., Wong, Y. T., Ho, R., Wasser, M., Du, T., Ng, W. T., et al. (2012). Effects of Hydrogen Peroxide on Wound Healing in Mice in Relation to Oxidative Damage. PLoS One 7 (11), e49215. doi:10.1371/journal.pone.0049215

Mandal, M. D., and Mandal, S. (2011). Honey: Its Medicinal Property and Antibacterial Activity. Asian Pac. J. Trop. Biomed. 1 (2), 154-160. doi:10.1016/S2221-1691(11)60016-6

Moffatt, C. J., Stanton, J., Murray, S., Doody, V., Davis, P. J., and Franks, P. J. (2014). A Randomised Trial to Compare the Performance of Oxyzyme ${ }^{\circledR}$ and Iodozyme ${ }^{\circledR}$ with Standard Care in the Treatment of Patients with Venous and Mixed Venous/Arterial Ulceration. Wound Med. 6, 1-10. doi:10.1016/ j.wndm.2014.08.002

Nair, D. P., Podgórski, M., Chatani, S., Gong, T., Xi, W., Fenoli, C. R., et al. (2014). The Thiol-Michael Addition Click Reaction: A Powerful and Widely Used Tool in Materials Chemistry. Chem. Mater. 26 (1), 724-744. doi: $10.1021 / \mathrm{cm} 402180 \mathrm{t}$

O'Brien, J., Wilson, I., Orton, T., and Pognan, F. (2000). Investigation of the Alamar Blue (Resazurin) Fluorescent Dye for the Assessment of Mammalian Cell Cytotoxicity. Eur. J. Biochem. 267 (17), 5421-5426. doi:10.1046/j.14321327.2000.01606.x

Pérez-Madrigal, M. M., Shaw, J. E., Arno, M. C., Hoyland, J. A., Richardson, S. M., and Dove, A. P. (2020). Robust Alginate/hyaluronic Acid Thiol-Yne ClickHydrogel Scaffolds with superior Mechanical Performance and Stability for Load-Bearing Soft Tissue engineeringAlginate/hyaluronic Acid Thiol-Yne Click-Hydrogel Scaffolds with superior Mechanical Performance and Stability for Load-Bearing Soft Tissue Engineering. Biomater. Sci. 8 (1), 405-412. doi:10.1039/c9bm01494b

Poldervaart, M. T., Goversen, B., De Ruijter, M., Abbadessa, A., Melchels, F. P. W., Öner, F. C., et al. (2017). 3D Bioprinting of Methacrylated Hyaluronic Acid (MeHA) Hydrogel with Intrinsic Osteogenicity. PLoS ONE 12 (6), e0177628-15. doi:10.1371/journal.pone.0177628

Rajan, M., Rajkumar, G., Farias Lima Guedes, T. J., Chagas Barros, R. G., and Narain, N. (2020). Performance of Different Solvents on Extraction of Bioactive Compounds, Antioxidant and Cytotoxic Activities in Phoenix Loureiroi Kunth Leaves. J. Appl. Res. Med. Aromatic Plants 17, 100247. doi:10.1016/ j.jarmap.2020.100247
Rapacka-Zdończyk, A., Woźniak, A., Michalska, K., Pierański, M., Ogonowska, P., Grinholc, M., et al. (2021). Factors Determining the Susceptibility of Bacteria to Antibacterial Photodynamic Inactivation. Front. Med. (Lausanne) 8, 642609. doi:10.3389/fmed.2021.642609

Ribeiro, J. S., Barboza, A. d. S., Cuevas-Suárez, C. E., da Silva, A. F., Piva, E., and Lund, R. G. (2020). Novel In-Office Peroxide-free Tooth-Whitening Gels: Bleaching Effectiveness, Enamel Surface Alterations, and Cell Viability. Sci. Rep. 10 (1), 1-8. doi:10.1038/s41598-020-66733-Z

Richbourg, N. R., Ravikumar, A., and Peppas, N. A. (2021). Solute Transport Dependence on 3D Geometry of Hydrogel Networks. Macromol. Chem. Phys. 222, 2100138: 1-7. doi:10.1002/macp.202100138

Rydholm, A., Anseth, K., and Bowman, C. (2007). Effects of Neighboring Sulfides and $\mathrm{pH}$ on Ester Hydrolysis in Thiol-Acrylate Photopolymers. Acta Biomater. 3 (4), 449-455. doi:10.1016/j.actbio.2006.12.001

Wang, D., Zhao, T., Zhu, X., Yan, D., Wang, W., et al. (2015). Bioapplications of Hyperbranched Polymers. Chem. Soc. Rev. 44 (12), 4023-4071. doi:10.1039/ C4CS00229F

Viedma, E., Juan, C., and Villa, J. (2012). VIM-2-Producing Multidrug-Resistant Pseudomonas Aeruginosa ST175 Clone, Spain. Emerg. Infect. Dis. 18 (8), 1235-1241. doi:10.3201/eid1808.111234

Wechsler, M. E., Stephenson, R. E., Murphy, A. C., Oldenkamp, H. F., Singh, A., and Peppas, N. A. (2019). Engineered Microscale Hydrogels for Drug Delivery, Cell Therapy, and Sequencing. Biomed. Microdevices 21 (2), 31. doi:10.1007/ s10544-019-0358-0

Weinstein, M. P. (2020). Performance Standards for Antimicrobial Susceptibility Testing, 30th edn. Clinical and Laboratory Standards Institute, CLSI supplement M100.

Wong, C. M., Wong, K. H., and Chen, X. D. (2008). Glucose Oxidase: Natural Occurrence, Function, Properties and Industrial Applications. Appl. Microbiol. Biotechnol. 78 (6), 927-938. doi:10.1007/s00253-008-1407-4

Xu, Q. A. S., Gao, Y., Guo, L., Creagh-Flynn, J., Zhou, D., Greiser, U., et al. (2018). A Hybrid Injectable Hydrogel from Hyperbranched PEG Macromer as a Stem Cell Delivery and Retention Platform for Diabetic Wound Healing. Acta. biomaterialia. 75, 63-74. doi:10.1016/j.actbio.2018.05.039

Zhang, J., Yong, H., A, S., Xu, Q., Miao, Y., Lyu, J., et al. (2018). Structural Design of Robust and Biocompatible Photonic Hydrogels from an In Situ Cross-Linked Hyperbranched Polymer System. Chem. Mater. 30 (17), 6091-6098. doi:10.1021/acs.chemmater.8b02542

Zhang, T., Qu, Y., Gunatillake, P. A., Cass, P., Locock, K. E. S., Blackman, L. D., et al. (2020). Honey-Inspired Antimicrobial Hydrogels Resist Bacterial Colonization through Twin Synergistic Mechanisms. Sci. Rep. 10 (1), 1-9. doi:10.1038/s41598-020-72478-6

Conflicts of Interest: JV, AS, SM, HT, and WW were employed by the company Blafar Ltd. The company provided the functionalized biomaterials for hydrogel fabrication in this paper.

The remaining authors declare that the research was conducted in the absence of any commercial or financial relationships that could be construed as a potential conflict of interest.

Publisher's Note: All claims expressed in this article are solely those of the authors and do not necessarily represent those of their affiliated organizations, or those of the publisher, the editors, and the reviewers. Any product that may be evaluated in this article, or claim that may be made by its manufacturer, is not guaranteed or endorsed by the publisher.

Copyright (๑ 2021 Vasquez, Idrees, Carmagnola, Sigen, McMahon, Marlinghaus, Ciardelli, Greiser, Tai, Wang, Salber and Chiono. This is an open-access article distributed under the terms of the Creative Commons Attribution License (CC BY). The use, distribution or reproduction in other forums is permitted, provided the original author(s) and the copyright owner(s) are credited and that the original publication in this journal is cited, in accordance with accepted academic practice. No use, distribution or reproduction is permitted which does not comply with these terms. 